\title{
Air bronchogram integrated lung ultrasound score to monitor community-acquired pneumonia in a pilot pediatric population
}

\author{
Riccardo Inchingolo ${ }^{1}$ (D) Roberto Copetti ${ }^{2} \cdot$ Andrea Smargiassi ${ }^{1} \cdot$ Rafael Emanuele Gerardi ${ }^{1}$. \\ Emanuele Giovanni Conte ${ }^{3}$. Giuseppe Maria Corbo ${ }^{1,4} \cdot$ Antonio Gatto $^{5}$. Chiara Pierandrei ${ }^{4} \cdot$ Lavinia Capossela $^{6}$. \\ Ilaria Lazzareschi ${ }^{5,7} \cdot$ Piero Valentini $^{5,7} \cdot$ Libertario Demi $^{8}$
}

Received: 4 November 2020 / Accepted: 26 November 2020 / Published online: 6 January 2021

(c) The Author(s) 2021

\begin{abstract}
Aims Chest ultrasound is a non-invasive method for evaluating children with suspected community-acquired pneumonia (CAP). We evaluated the prognostic role of change of ultrasonographic (US) air bronchogram in management of CAP in terms of: rate of complicated CAP, change of empiric antibiotic therapy, relationship to defervescence time, and length of hospitalization.

Methods Patients with CAP and radiographic evidence of lung consolidation were prospectively enrolled. Chest US examinations were performed within $12 \mathrm{~h}$ from admission and after $48 \mathrm{~h}$. A new grading system (USINCHILD score) based on presence and features of air bronchogram was adopted.

Results Thirty six patients were stratified into two groups according to the presence of an increase of at least 1 grade of US score ( $\Delta$ US grade), expression of an improvement of lung consolidation. $\Delta$ US grade after $48 \mathrm{~h} \geq 1$ was associated with an increased risk of complicated CAP ( $p$ value 0.027$)$ and a longer defervescence time ( $p$ value 0.036$)$. Moreover, $\Delta$ US grade $\geq 1$ was predictive of a short hospitalization ( $p$ value 0.008 ).
\end{abstract}

Conclusions USINCHILD score could be an innovative biotechnology tool for the management of pediatric CAP.

Trial registration number and date of registration NCT03556488, June 14, 2018.

Keywords Air bronchogram $\cdot$ Children $\cdot$ Imaging $\cdot$ Score $\cdot$ Ultrasound $\cdot$ Pneumonia

$\begin{array}{ll}\text { Abbreviations } \\ \text { CAP } & \text { Community-acquired pneumonia } \\ \text { US } & \text { Ultrasonographic } \\ \text { BTS } & \text { British Thoracic Society } \\ \text { CXR } & \text { Chest radiograph }\end{array}$

Electronic supplementary material The online version of this article (https://doi.org/10.1007/s40477-020-00547-7) contains supplementary material, which is available to authorized users.

Riccardo Inchingolo

riccardo.inchingolo@policlinicogemelli.it

1 Pulmonary Medicine Unit, UOC Pneumologia, Fondazione Policlinico Universitario A. Gemelli IRCCS, Largo Gemelli, 8, 00168 Rome, Italy

2 Emergency Department, University Hospital Cattinara, Trieste, Italy

3 Pulmonary Medicine Unit, Ospedale "C. E G. Mazzoni”, Ascoli Piceno, Italy

4 UOC Pneumologia, Università Cattolica del Sacro Cuore,

Roma, Italy
NPS Nasopharyngeal swab specimens

CRP C-reactive protein

SD Standard deviation

WBC White blood cells

$\triangle \mathrm{US}$ Change of USINCHILD score 


\section{Introduction}

Pneumonia is a leading cause of childhood morbidity worldwide [1]. Each year, 2 million children younger than 5 year die of pneumonia, representing $20 \%$ of all deaths in children within this age group [2]. Although difficult to quantify, it is believed that up to 155 million cases of pneumonia occur in children every year worldwide [2]. In the developed world, the annual incidence of pneumonia is 3-4 cases per 100 children, 5 years old [3, 4].

According to the British Thoracic Society (BTS) guidelines, clinical symptoms and signs are usually sufficient to diagnose community-acquired pneumonia (CAP) in children [8]. Thus, the BTS guidelines do not recommend performing chest radiograph (CXR) in all children with typical pneumonia signs and symptoms. On the other hand, recent BTS Paediatric Pneumonia Audit revealed that in many children suspected of CAP, chest radiograph was done to confirm the diagnosis. Moreover, subsequent follow-up radiographs were commonly overused, causing unnecessary radiation exposure [9].

Many studies showed that ultrasound (US) findings of lung and pleural diseases described in adults are also found in pediatric patients [7-11] and that lung US is a good clinical tool to detect consolidation in children affected by pneumonia [12-15]. A recent meta-analysis of these studies highlights the attractive diagnostic role of US for pediatric CAP [16].

In 2009, Lichtenstein and co-workers showed that in patients with alveolar consolidation displaying air bronchograms on ultrasound, the dynamic air bronchogram indicated pneumonia, distinguishing it from resorptive atelectasis [17]. Air bronchograms are punctiform or linear hyperechoic artifacts within the consolidation. Dynamic air bronchogram is the term used for the centrifugal inspiratory dynamic of air bronchograms, ultrasonographic finding usually detected in lung consolidation due to pneumonia. Conversely, static air bronchograms are found in resorptive atelectasis [17].

Previous studies explored if LUS could be useful to diagnose and monitor the response to treatment of pneumonias in adults $[18,19]$.

In 2013, Caiulo et al. showed LUS is not inferior to CXR in identifying pleuro-pulmonary alterations in children with suspected pneumonia. During the course of the disease, the lack of ultrasonographic improvement was related to the lack of clinical recovery [20]. Bouhemad et al. showed that LUS can evaluate the size of the consolidated area and the improvement in lung aeration [21]. More recently, Musolino et al. suggested that a deep and fixed air bronchogram in the initial LUS might be able to predict the development of complicated pneumonia [22].
Lung US follow-up allows to verify complications, to avoid additional radiation exposures, and to monitor the evolution of the disease [11,31].

We evaluated the prognostic role of the change of air bronchogram, a typical ultrasonographic finding of lung consolidation due to pneumonia, in the management of CAP in terms of: (1) impact on rate of complications; (2) change of antibiotic therapy not guided by microbiological examinations; (3) relationship to the time of resolution of clinical signs; (4) length of hospitalization.

\section{Materials and methods}

\section{Study subjects}

This was a pilot single-center observational prospective study performed at Fondazione Policlinico Universitario A. Gemelli IRCCS in Rome, Italy. Ethical approval for the study was obtained [13528/ID:2001]. Children with age from 1 to 18 years, with suspected CAP [5] and radiographic evidence of lung consolidation, admitted to Paediatric Unit, were consecutively enrolled. A written informed consent was given from parents. Children with history of gestational age $<36$ weeks, a previous diagnosis of cystic fibrosis or congenital pulmonary disease, were excluded.

\section{Study design}

The current primary outcomes were: the rate of uncomplicated CAP; the time to resolution of fever, the change of antibiotic therapy not guided by microbiological examinations, and, finally, the length of hospitalization.

The lack of previously published studies exploring the same US score led us to plan an estimated enrollment of at least 30 patients in 1 year.

\section{Methods}

At admission, the pediatric evaluated clinical signs of respiratory distress [i.e., tachypnea, dyspnea, retractions (suprasternal, intercostals, or subcostal), grunting, and nasal flaring, apnea], presence of altered mental status, pulse oximetry values $\leq 90 \%$ on room air and temperature. Furthermore, microbiologic tests (nasopharyngeal swab specimens, [NPS] and pneumococcal urinary antigen) to detect causative pathogens of CAP, and laboratory tests (complete blood cell count, acute-phase reactants, and C-reactive protein [CRP]) were performed. Finally, if chest radiography (CXR) was performed before the admission to Paediatric Unit, the radiological exam was not repeated.

US evaluation was performed by Pulmonologists using MyLab Alpha (Esaote S.p.a., Rome, Italy) machine with 
convex (3.5-5 MHz) and linear (7.5-12 MHz) probes based on the size of the chest. We did not adopt the eight-zone scanning technique usually suggested in emergency setting [32]. Conversely, we explored all chest regions that can be scanned implementing the growing belief that ultrasonographic insonation is a pillar of bedside physical examination $[33,34]$. The first examination was performed within $12 \mathrm{~h}$ from admission. The Pulmonologists could identify signs of respiratory distress and/or low values of $\mathrm{SpO}_{2}$, if present, but they were blinded to clinical findings such as heart rate, blood pressure, and completely blind to radiological and biohumoral findings.

To characterize the lung consolidation from ultrasonographic point of view, a new grading system (USINCHILD score) based on the presence and the features of air bronchogram was adopted.

This score assigns a grade according to these features. The grade 0 indicates a lung consolidation without air bronchogram (video 0); the grade 1 a lung consolidation with static air bronchogram (video 1); the grade 2 a lung consolidation with dynamic air bronchogram (video 2); the grade 3 a lung consolidation with both dynamic air bronchogram and areas of lung recruitment (video 3); the grade 4 a focal sonographic interstitial syndrome (video 4); finally, the grade 5 characterized by normal pleural-parenchymal pattern, expression of resolution of lung consolidation (video $5)$.

We adopted a score with the lowest values expression of a greater compromise of lung parenchyma due to inflammation/infection with no evidence of air bronchogram (grade 0 ) or with only static air bronchogram (grade 1), expression of air trapped in the parenchyma affected by pneumonia. Conversely, the highest values of the score describe the resolution of consolidative process with evidence of vertical artifacts originating from the pleural line-usually described as sonographic interstitial syndrome (video 4), until the normal ultrasonographic pattern is restored (video 5) (Fig. 1).

The air bronchogram described in grade 2 is usually arborescent, an important feature for the scoring definition, previously defined as a specific sign for both community- and ventilator-acquired pneumonia $[21,23,26]$.

The features of the grade 3 include a lung consolidation with both dynamic air bronchogram and areas of lung recruitment. Moreover, the identification of this grade requires the presence of the shred sign —a static sonographic sign observed in lung consolidation due to the deeper border

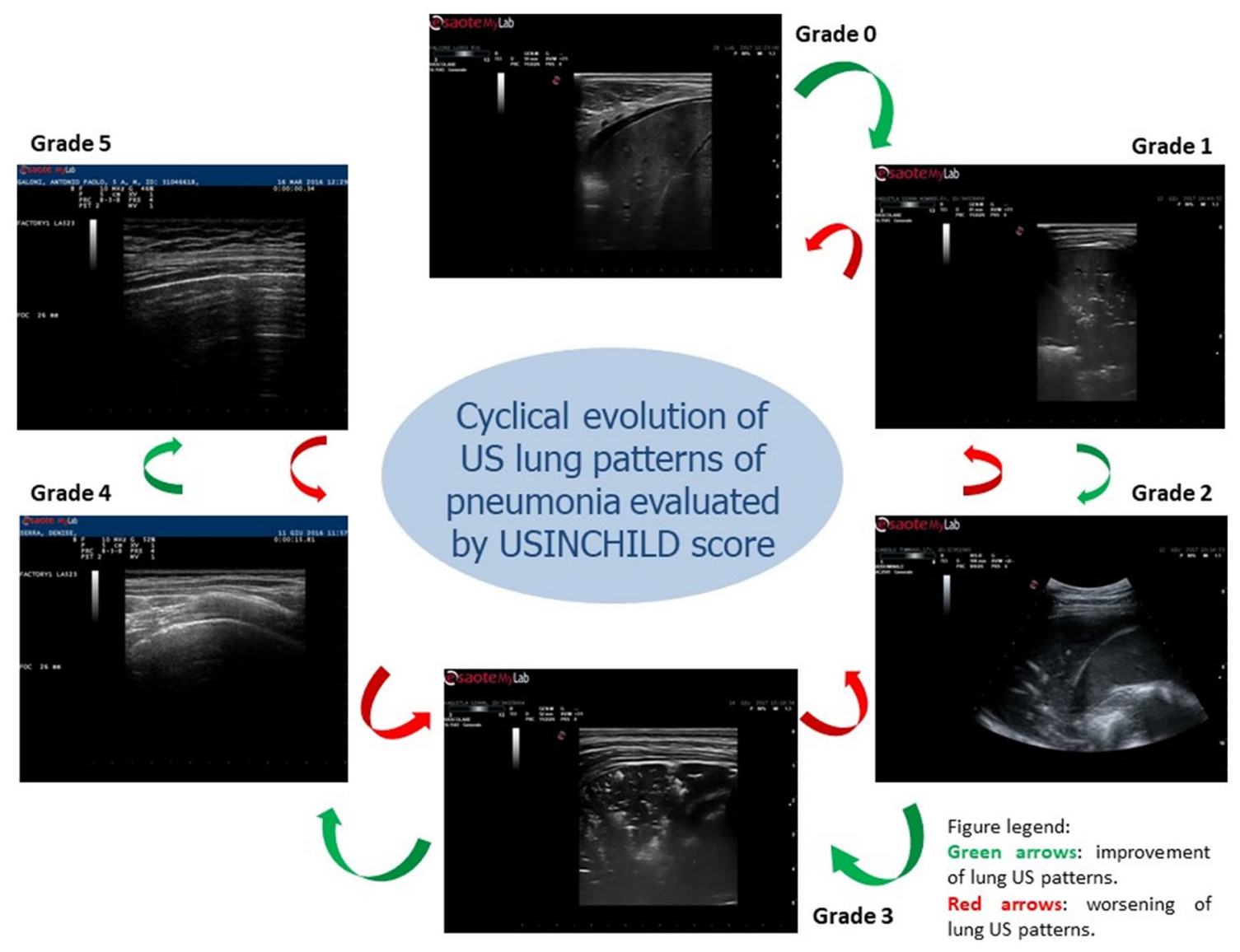

Fig. 1 Cyclical evolution of US lung patterns of pneumonia evaluated by USINCHILD score 
of consolidated lung tissue, in contact with the aerated lung, usually shredded and irregular [21, 30].

The grade 4, named sonographic interstitial syndrome, described a pneumogenic pattern of sonographic features of B lines (unusual septal disposition of B lines, blurred, uneven, coalescent B lines and white lung, non-modulated B lines, pseudo B lines) and pleural line (irregular with reduced pleural sliding) in an area previously affected by a consolidation process [35].

The Pulmonologists (RI, AS, REG, and EGC), with at least 5 years' experience in ultrasound collected and stored images and videos (10 s). All US images and clips were reviewed by two Pulmonologists of the Research Group (RI and AS) and by an expert Clinician in chest US (RC), blind to other data to evaluate inter-observational variability by Kappa statistic.

In case of clinical deterioration, children underwent further US evaluations according to pediatric indications.

The identification of complicated pneumonia was based on the presence of: (1) severe respiratory failure requiring assisted ventilation, (2) septicaemia, (3) pleural effusions and empyema, and 4) necrotising pneumonias.

\section{Analysis}

The outcome measures were the rate of complicated CAP at $48 \mathrm{~h}$, the change of empiric antibiotic therapy at $48 \mathrm{~h}$, the defervescence time expressed in hours, and, finally, the length of hospitalization expressed in days.

Descriptive data were reported as mean values and standard deviation (SD) for continuous variables (age, WBC, $\mathrm{CRP}$, time to resolution of fever, and length of hospitalization), whereas frequency of clinical findings, rate of complicated CAP, and rate of upgrade of empirical antibiotic therapy were reported as percentages. Finally, also US air bronchogram grades (at admission and after 48hours) and change of the grade after $48 \mathrm{~h}$ [ $\Delta$ US grade] were reported as percentages.

Comparisons (at admission and after $48 \mathrm{~h}$ ) were made by Sign test for clinical findings and Wilcoxon signed-rank test for $\Delta$ US.

After the stratification of US grades in a post hoc analysis, we identified a priori two groups of patients according to the presence of an increase of at least 1 grade of US score, a plausible clinical expression of an ultrasonographic improvement of lung consolidation.

The first outcome, the association of the change of air bronchogram with the rate of complicated respiratory infections, was tested with Fisher's exact test. Then, an unweighted logistic regression analysis was performed to evaluate the association between the evolution of the CAP (complicated/uncomplicated) and the presence of an increase of at least 1 grade of US score after $48 \mathrm{~h}$ (US grade $\Delta \geq 1$ ).
Moreover, Fisher's exact test was also used to test the correlation between the upgrade of empiric antibiotic therapy and change of USINCHILD score.

Instead, to assess the association between the change of the therapy and several variables (US grade $\Delta \geq 1$, the change of WBC and CRP after $48 \mathrm{~h}$ ), we performed a logistic regression analysis.

Subsequently, a Receiver-Operating Characteristic (ROC) curve analysis was performed to test sensitivity/specificity of variations of USINCHILD score and dichotomic variables (complicated CAP and upgrade of antibiotic therapy).

The association between the time to resolution of fever and the presence of an increase of at least 1 grade of US score after $48 \mathrm{~h}$ (US grade $\Delta \geq 1$ ) was tested by Cox regression. Finally, this test was also used to evaluate the relationship between the days of hospitalization and the change of USINCHILD score. Correlation analysis were also adjusted for sex and age.

STATA version 11 was used for data analysis, data management, and graphics.

\section{Results}

From May to December 2018, we collected data from all patients who met the inclusion criteria and for whom all US images and clips-at admission and after $48 \mathrm{~h}$-were considered of high quality by the Research Team and the expert Reviewer.

Study population was composed by 36 patients (18 females) with average age of $5 \pm 4$ years.

Demographic and clinical findings of enrolled patients are shown in Table 1.

Nine patients (25\%) had a complicated CAP and 17 patients $(47 \%)$ underwent an upgrade of empiric antibiotic therapy. Mean values of time to resolution of fever and length of hospitalization were $89 \pm 62 \mathrm{~h}$ and $11 \pm 7$ days, respectively.

The inter-observer agreement (Kappa statistic) of USINCHILD score was 0.85 as concerns the evaluation performed at admission, and 0.89 as concerns the evaluation performed after $48 \mathrm{~h}$.

The frequency distribution of both USINCHILD score at admission and after $48 \mathrm{~h}$ and the change of USINCHILD score after $48 \mathrm{~h}(\Delta \mathrm{US})$ are reported in Table 2 . The change of USINCHILD score after $48 \mathrm{~h}$ was statistically significant (Wilcoxon signed-rank test, $\mathrm{p}$ value: 0.0001 ).

Moreover, the patients were dichotomized into two groups according to the presence of an increase of at least 1 grade of USINCHILD score ( $\Delta$ US grade) and expression of an improvement of lung consolidation.

The first outcome was the association of the change of USINCHILD score with the rate of complicated respiratory 
Table 1 Demographics and clinical findings

\begin{tabular}{|c|c|c|c|c|}
\hline Patients & [No.] & 36 & & \\
\hline Female & [No., \% of sample] & $18(50)$ & & \\
\hline \multirow[t]{2}{*}{ Age } & [years, $\mathrm{M}^{1}, \mathrm{SD}^{2}$ ] & $5( \pm 4)$ & & \\
\hline & & At admission & After $48 \mathrm{~h}$ & \\
\hline $\mathrm{WBC}^{3}$ & {$\left[\mathrm{M}, \mathrm{SD}, \mathrm{x} 10^{9} / \mathrm{L}\right]$} & $13.8( \pm 7.3)$ & $9.2( \pm 3.8)$ & \\
\hline \multirow[t]{2}{*}{$\mathrm{CRP}^{4}$} & {$[\mathrm{M}, \mathrm{SD}, \mathrm{mg} / \mathrm{L}]$} & $92.4( \pm 116.3)$ & $45.1( \pm 53.9)$ & \\
\hline & [No., \% of sample] & At admission & After $48 \mathrm{~h}$ & $p$ value $^{5}$ \\
\hline Cough & & $22(61)$ & $4(11)$ & 0.0001 \\
\hline Dyspnea & & $17(47)$ & $5(13)$ & 0.0002 \\
\hline Respiratory Failure & & $7(19)$ & $2(5)$ & 0.0313 \\
\hline Fever & & $33(91)$ & $12(33)$ & 0.0001 \\
\hline Gastrointestinal symptoms & & $8(22)$ & $3(8)$ & NS \\
\hline Malaise & & $21(58)$ & $9(25)$ & 0.0002 \\
\hline Sputum & & $13(36)$ & $4(11)$ & 0.0020 \\
\hline \multicolumn{5}{|l|}{ Outcomes } \\
\hline Complicated CAP & & No. (\% of sample) & $9(25)$ & \\
\hline Upgrade of empiric antibiotic therapy & & No. (\% of sample) & $17(47)$ & \\
\hline Time to resolution of fever & & Hours (mean, SD) & $89( \pm 62)$ & \\
\hline Length of hospitalization & & Days (mean, SD) & $11( \pm 7)$ & \\
\hline \multicolumn{5}{|l|}{${ }^{1}$ Mean value } \\
\hline \multicolumn{5}{|l|}{${ }^{2}$ Standard deviation } \\
\hline \multicolumn{5}{|l|}{${ }^{3}$ White blood cells } \\
\hline${ }^{4} \mathrm{C}$ reactive protein & & & & \\
\hline${ }^{5}$ Sign test & & & & \\
\hline
\end{tabular}

infections (Table 3). Patients with evidence of improvement of USINCHILD score ( $\Delta$ US grade $\geq 1$ ) showed a low rate of complicated CAP (Fisher's exact test, $p$ value: 0.0001). Moreover, the evidence of $\Delta U S$ grade $\geq 1$ was associated with a statistically significant increase of risk of complicated CAP ( $p$ value: 0.027 ). Finally, the Table 3 shows the sensitivity and specificity to identify complicated/uncomplicated CAP for each degree of USINCHILD change after $48 \mathrm{~h}$ (area under ROC curve: 0.87 ).

Table 4 shows the correlation between the change of USINCHILD score and the upgrade of antibiotic therapy not guided by microbiological examinations (Fisher's exact test, $p$ value 0.0467 ).

The presence of an increase of at least 1 grade of USINCHILD score- $\Delta$ US grade $\geq 1$-was associated with the upgrade of empiric antibiotic therapy (logistic regression, $p$ value: 0.016 ). The area under ROC curve of the change of USINCHILD was 0.87 .

The evidence of USINCHILD score $\geq 1$ was linearly associated with a statistically significant increase of defervescence time ( $p$ value: 0.036 ), as reported in Table 5.

Finally, the increase of at least 1 grade of the ultrasonographic score after $48 \mathrm{~h}$ was predictive of the length of hospitalization ( $p$ value: 0.008 ) (Table 6) (Fig. 2). In particular, the presence of $\Delta$ US grade $\geq 1$ after $48 \mathrm{~h}$ was associated with a reduction of 7 days of hospitalization.

\section{Discussion}

Our study confirms that the evaluation of the characteristics of air bronchogram, a typical ultrasonographic finding of lung consolidation due to pneumonia, has an important impact in the management of pediatric CAP.

The first description of this ultrasonographic sign of alveolar consolidation, useful to differentiate pneumoniae from resorptive atelectasis, was reported by Lichtenstein et al. [17].

More recent studies confirmed and detailed the initial finding reported by Lichtenstein on dynamic air bronchogram as a sign ruling out atelectasis. The "linear arborescent" shape has then been identified as specific for pneumonia (either community-acquired [36] and ventilatorassociated [38]). Moreover, both these studies proposed to use the air bronchogram to monitor pneumonia recovery [36, 37].

Recently, the Point of Care Ultrasound (POCUS) Working Group of the European Society of Paediatric and Neonatal Intensive Care (ESPNIC) provided evidence-based clinical guidelines for the use of POCUS in critically ill neonates and children [38]. The authors highlighted the diagnostic applications of LUS to detect pneumonia in neonates and children, remarking as typical ultrasonographic signs the presence of consolidations, dynamic air bronchograms, 
Table 2 Frequency distribution of USINCHILD score

\begin{tabular}{llll}
\hline Grade $^{*}$ & $\begin{array}{l}\text { At admission } \\
\text { Frequency (\% of sample) }\end{array}$ & After 48h & $\begin{array}{l}\Delta \text { US }^{\ddagger} \\
p \text { value }\end{array}$ \\
\hline 0 & $4(11)$ & $1(2)$ & 0.0001 \\
1 & $15(41)$ & $7(19)$ & \\
2 & $4(11)$ & $5(13)$ & \\
3 & $9(25)$ & $5(13)$ & \\
4 & $4(11)$ & $13(36)$ & \\
5 & 0 & $5(13)$ & \\
Frequency distribution of $\Delta$ US & & \\
Value & Frequency (\% of sample) & & \\
-1 & $1(2)$ & & \\
0 & $12(33)$ & & \\
1 & $8(22)$ & & \\
2 & $10(27)$ & & \\
3 & $4(11)$ & & \\
4 & $1(2)$ & & \\
\hline
\end{tabular}

*0: absent

${ }^{1}$ Static

${ }^{2}$ Dynamic

${ }^{3}$ Dynamic with areas of lung recruitment

${ }^{4}$ Focal interstitial sonographic syndrome

${ }^{5}$ Resolution of consolidation

${ }^{¥} \Delta$ US: difference between USINCHILD score after 48hours and at admission

${ }^{\ddagger}$ Wilcoxon signed rank test

vertical artifacts (B lines), and pleural effusion. Moreover, it was recognized higher diagnostic accuracy of LUS compared with chest X-rays for the diagnosis of pneumonia [16].

To our knowledge, USINCHILD score is the first application of the prognostic role of ultrasonographic air bronchogram in the management of CAP in children.

In fact, the change of USINCHILD score is significantly related to the rate of complicated respiratory infections. Patients without a change of US score of at least 1 grade after $48 \mathrm{~h}$ are at risk of complicated CAP. Moreover, our data suggest that the presence of USINCHILD score after $48 \mathrm{~h} \leq 1$ is associated with an increased risk of complicated CAP.

Many lung ultrasound scores (LUS) are currently used to perform a qualitative assessment of lung aeration and guide respiratory care in lung disorders, because this is strongly recommended (level of evidence A) by current guidelines [40].

Raimondi et al. [40, 41] described the usefulness of LUS in predicting neonatal intensive care unit (NICU) admission or need for intubation, using only 3 simple LUS patterns.

In 2015, Brat et al. studied the diagnostic accuracy of a neonatal adapted LUS score to evaluate oxygenation and need for surfactant administration. The authors showed a good reliability to predict surfactant administration in preterm babies with a gestational age (GA) less than 34 weeks under continuous positive airway pressure [42].

In 2016, Rodríguez-Fanjul et al. evaluated the usefulness of LUS for prediction of the need for respiratory support in newborns older than 32 weeks showing good correlation with the need for mechanical ventilation and long respiratory support [43].

More recently, De Martino et al. explored the diagnostic accuracy of LUS in predicting the need for surfactant treatment and re-treatment in extremely preterm neonates with respiratory distress syndrome on CPAP [44].

As concern the possible association of USINCHILD score with the upgrade of antibiotic therapy not guided by microbiological examinations, our results show a significant correlation.

These results are concordant with the current guidelines for the management of pediatric CAP. In fact, the initial antibiotic treatment of CAP is empiric, because the pathogen is rarely known at the time of diagnosis. Children receiving adequate therapy should demonstrate clinical and also laboratory signs of improvement within 48-72 h. For children whose condition deteriorates after admission and initiation of antimicrobial therapy or who show no improvement within $48-72 \mathrm{~h}$, it is often required an upgrade in the antibiotic therapy and further investigation to identify whether the original pathogen persists, whether it has developed resistance to the agent used, or whether there is a new secondary infecting agent.

The third outcome was the prognostic role of USINCHILD score on the time of resolution of clinical signs. We chose the fever as the most relevant clinical sign, because it was present in almost all patients at admission. Results show a strong association between the time to resolution of fever and the USINCHILD score after $48 \mathrm{~h}$ from admission.

Finally, our study demonstrates a clinically significant association of USINCHILD score with the length of hospitalization. Children with a difference of the grade equal or greater than 1 could present until 7 days of hospitalization less than patients without improvement of echographic score.

Our study has some limitations. First of all, the number of enrolled patients is limited. The number of patients enrolled is influenced by: (1) missing ultrasound data, (2) ultrasound data considered of not high quality, and (3) summer period within the time interval considered; second, the exploratory nature of the analysis. Nevertheless, the lack of previously published studies exploring the prognostic role of air bronchogram sign in pediatric field led us to preventively define a sample size of at least 30 patients in 1 year. 
Table 3 The association of USINCHILD score with the rate of complicated respiratory infections

\begin{tabular}{|c|c|c|c|c|}
\hline \multicolumn{5}{|c|}{ Comparison between rate of complicated CAP and change of USINCHILD score } \\
\hline \multirow[b]{2}{*}{ Uncomplicated CAP } & \multirow{2}{*}{$\begin{array}{l}\text { US Grade } \Delta^{¥}<1 \\
5\end{array}$} & \multicolumn{2}{|l|}{ US Grade $\Delta^{¥} \geq 1$} & \multirow{2}{*}{$\begin{array}{c}p \text { value } \\
0.0001\end{array}$} \\
\hline & & 22 & 27 & \\
\hline Complicated CAP & 8 & 1 & 9 & \\
\hline Tot & 13 & 23 & 36 & \\
\hline \multicolumn{5}{|c|}{ Logistic regression of rate of complicated CAP } \\
\hline Variable & Odds ratio & Standard error & $95 \%$ conf. interval & $p$ value \\
\hline US Grade $\Delta^{¥} \geq 1$ & 0.0038 & 0.0095 & $(0.0000-0.5259)$ & 0.027 \\
\hline$\Delta \mathrm{WBC} * *$ & 1.0216 & 0.1148 & $(0.8197-1.2734)$ & 0.849 \\
\hline$\Delta \mathrm{CRP} * * *$ & 0.9841 & 0.0094 & $(0.9659-1.0027)$ & 0.093 \\
\hline Sex & 3.2793 & 4.7661 & $(0.1900-56.6128)$ & 0.414 \\
\hline Age & 1.3290 & 0.2346 & $(0.9403-1.8784)$ & 0.107 \\
\hline \multicolumn{5}{|l|}{ ROC curve analysis } \\
\hline$\overline{\text { US grade } \Delta^{¥}}$ & & Specificity & & $\overline{\text { Sensitivity }}$ \\
\hline-1 & & 0 & & 0.1111 \\
\hline 0 & & 0.1852 & & 0.8889 \\
\hline 1 & & 0.4815 & & 0.8889 \\
\hline 2 & & 0.8519 & & 0.8889 \\
\hline 3 & & 0.963 & & 1 \\
\hline 4 & & 1 & & 1 \\
\hline
\end{tabular}

${ }^{¥}$ US Grade $\Delta$ : difference between USINCHILD score after 48hours and at admission

*Fisher's exact test.

** $\triangle \mathrm{WBC}$ : the difference between WBC evaluated after 48h of follow-up and WBC at admission

$* * * \Delta \mathrm{CRP}$ : the difference between CRP evaluated after $48 \mathrm{~h}$ of follow-up and CRP at admission

Table 4 The association of the change of USINCHILD score with the upgrade of antibiotic therapy

Comparison between upgrade of antibiotic therapy and change of USINCHILD score

\begin{tabular}{lllll}
\hline Not upgrade Ab therapy & 4 & 15 & 19 & $p$ value $^{*}$ \\
\hline Upgrade Ab therapy & & 9 & 8 & 17 \\
& Tot. & 13 & 23 & 36 \\
\hline
\end{tabular}

Logistic regression of upgrade of antibiotic therapy

\begin{tabular}{lllll}
\hline Variable & Odds ratio & Standard error & $95 \%$ conf. interval & $p$ value \\
\hline US grade $\Delta^{\ddagger} \geq 1$ & 0.0801 & 0.0843 & $(0.0102-0.6304)$ & 0.016 \\
$\Delta$ WBC $* *$ & 1.0572 & 0.0688 & $(0.9307-1.2009)$ & 0.392 \\
$\Delta$ CRP*** & 0.9883 & 0.0063 & $(0.9759-1.0008)$ & 0.066 \\
Age & 1.1273 & 0.1171 & $(0.9196-1.3820)$ & 0.249 \\
Sex & 2.0922 & 1.9665 & $(0.3315-13.2024)$ & 0.432 \\
\hline
\end{tabular}

${ }^{\ddagger}$ US Grade $\Delta$ : difference between USINCHILD score at admission and after $48 \mathrm{~h}$

*Fisher's exact test

** $\triangle \mathrm{WBC}$ : the difference between WBC evaluated after $48 \mathrm{~h}$ of follow-up and WBC at admission

$* * * \triangle \mathrm{CRP}$ : the difference between CRP evaluated after $48 \mathrm{~h}$ of follow-up and CRP at admission 
Table 5: USINCHILD as predictor of resolution of fever*

\begin{tabular}{llllc}
\hline Predictor variables & Haz. ratio & Standard error & $95 \%$ conf. interval & $p$ value \\
\hline US Grade $\Delta^{\ddagger} \geq 1$ & 2.3760 & 0.98 & $(1.0565-5.3436)$ & 0.036 \\
Age & 1.0066 & 0.0425 & $(0.9266-1.0935)$ & 0.876 \\
Sex & 0.8199 & 0.2914 & $(0.4086-1.6456)$ & 0.576 \\
\hline
\end{tabular}

*Defervescence time, expressed in hours, was chosen as expression of resolution of clinical signs

${ }^{\ddagger}$ US Grade $\Delta$ : difference between USINCHILD score after 48hours and at admission. Cox regression analysys of defervescence time.

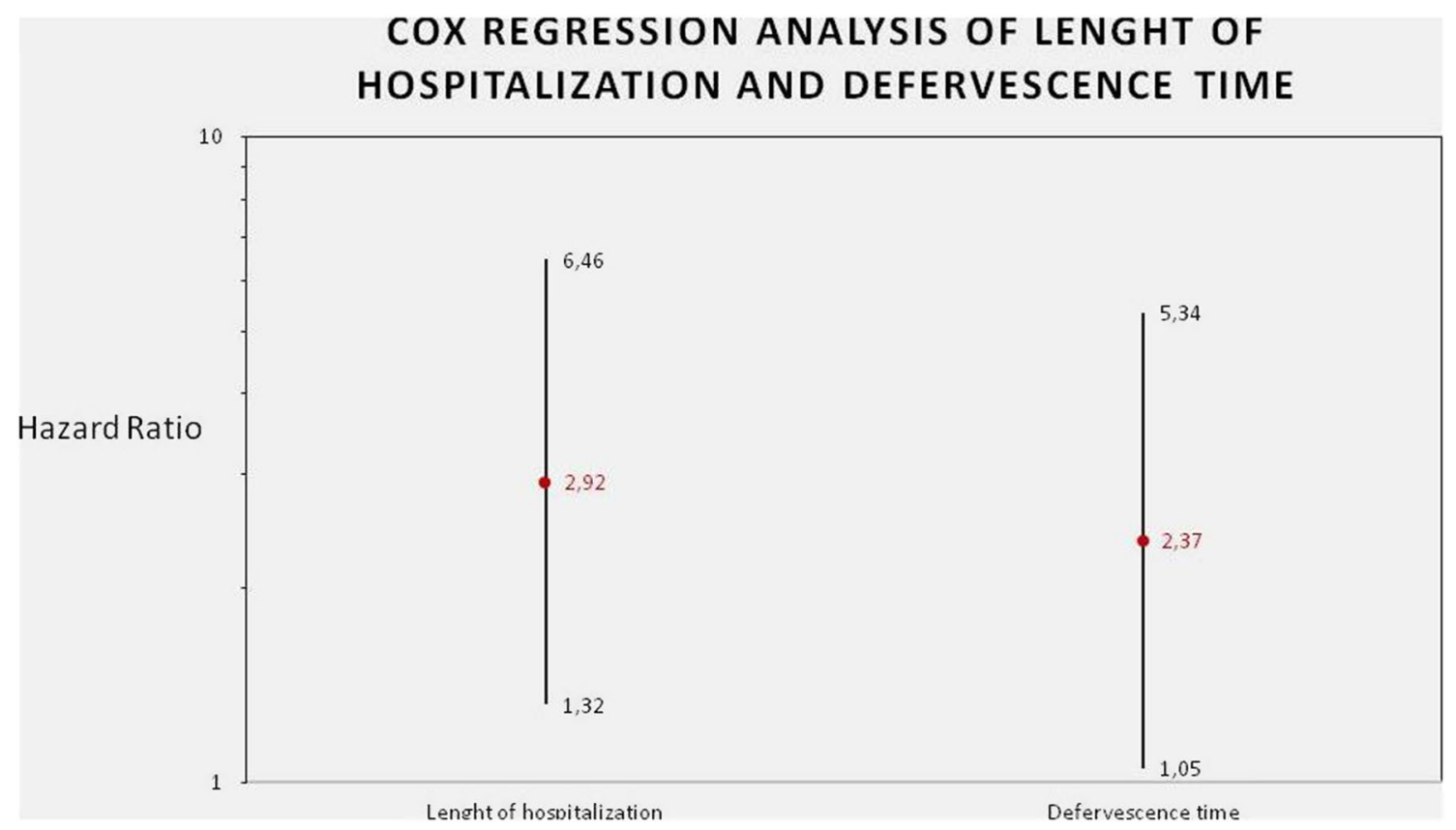

Fig. 2 Cox regression analysis of lenght of hospitalization and defervescence time

Table 6 USINCHILD as predictor of length of hospitalization

\begin{tabular}{lllll}
\hline Predictor variables & Haz. ratio & Standard error & $95 \%$ conf. interval & $p$ value \\
\hline US grade $\Delta^{\ddagger} \geq 1$ & 2.9241 & 1.1831 & $(1.3231-6.4623)$ & 0.008 \\
Age & 0.8982 & 0.0436 & $(0.8167-0.9879)$ & 0.027 \\
Sex & 0.6895 & 0.2482 & $(0.3405-1.3962)$ & 0.302 \\
\hline
\end{tabular}

${ }^{\ddagger}$ US Grade $\Delta$ : difference between USINCHILD score after 48hours and at admission. Cox regression analysys of lenght of hospitalization expressed as days.

\section{Conclusions}

In conclusion, our results demonstrate a prognostic role of the evaluation of the characteristics and the change of the air bronchogram in the management of CAP in children. Ultrasound examination at admission and after $48 \mathrm{~h}$ could give important information regarding the possible evolution toward a complicated respiratory infection.

Moreover, it may also help to identify children with favorable clinical course in terms of resolution of the clinical signs and length of hospitalization allowing to optimize the management of inpatient.

This study highlights that chest US is an excellent clinical tool not only for the diagnosis but also for the management of pediatric CAP.

Author contributions All authors contributed to the study conception and design. Material preparation, data collection, and analysis were performed by RI, RC, AS, REG, and EGC. The first draft of the manuscript was written by RI and all authors commented on previous 
versions of the manuscript. All authors read and approved the final manuscript.

Funding Open access funding provided by Università Cattolica del Sacro Cuore within the CRUI-CARE Agreement. The project was done with no specific support.

Availability of data and materials Deidentified individual participant data will not be made available.

\section{Compliance with ethical standards}

Conflict of interest The authors have no conflicts of interest relevant to this article to disclose.

Ethics approval Ethical approval for the study was obtained [13528/ ID:2001] from Fondazione Policlinico Universitario A. Gemelli IRCCS in Rome, Italy.

Consent to participate A written informed consent was given from parents.

Open Access This article is licensed under a Creative Commons Attribution 4.0 International License, which permits use, sharing, adaptation, distribution and reproduction in any medium or format, as long as you give appropriate credit to the original author(s) and the source, provide a link to the Creative Commons licence, and indicate if changes were made. The images or other third party material in this article are included in the article's Creative Commons licence, unless indicated otherwise in a credit line to the material. If material is not included in the article's Creative Commons licence and your intended use is not permitted by statutory regulation or exceeds the permitted use, you will need to obtain permission directly from the copyright holder. To view a copy of this licence, visit http://creativecommons.org/licenses/by/4.0/.

\section{References}

1. Wardlaw T, Salama P, Johansson EW, Mason E (2006) Pneumonia: the leading killer of children. Lancet (Lond Engl) 368:1048-1050

2. World Health Organization. Pneumonia. Fact sheet No. 331. 2009. Available at: http://www.who.int/mediacentre/factsheets/fs331/en/ index.html. Accessed 7 September 2010.

3. McCracken GH (2000) Etiology and treatment of pneumonia. Pediatr Infect Dis J 19:373-377

4. McIntosh K (2002) Community-acquired pneumonia in children. N Engl J Med 346:429-437

5. Harris, M., Clark, J., Coote, N., et al (2011) British thoracic society guidelines for the management of community acquired pneumonia in children: update 2011. Thorax. 66:ii1-23.

6. Bowen S-JM, Thomson AH (2013) British thoracic society paediatric pneumonia audit: a review of 3 years of data. Thorax 68:682-683

7. Lichtenstein D (2009) Ultrasound examination of the lungs in the intensive care unit. Pediatr Crit Care Med 10:693-698

8. Copetti R, Cattarossi L (2008) Ultrasound diagnosis of pneumonia in children. Radiol Med 113:190-198

9. Coley BD (2005) Pediatric chest ultrasound. Radiol Clin North Am. 405-418.

10. Riccabona M (2008) Ultrasound of the chest in children (mediastinum excluded). Eur Radiol 18:390-399
11. Urbankowska E, Krenke K, Drobczyński Ł, Korczyński P, Urbankowski T, Krawiec M et al (2015) Lung ultrasound in the diagnosis and monitoring of community acquired pneumonia in children. Respir Med 109:1207-1212

12. Jones BP, Tay ET, Elikashvili I, Sanders JE, Paul AZ, Nelson BP et al (2016) Feasibility and safety of substituting lung ultrasound for chest X-ray when diagnosing pneumonia in children: a randomized controlled trial. Chest 150:131-138

13. Nazerian P, Cerini G, Vanni S, Gigli C, Zanobetti M, Bartolucci $M$ et al (2016) Diagnostic accuracy of lung ultrasonography combined with procalcitonin for the diagnosis of pneumonia: a pilot study. Crit Ultrasound J 8:17

14. Iuri D, De Candia A, Bazzocchi M (2009) Valutazione del quadro polmonare nei pazienti pediatrici con sospetto clinico di polmonite: apporto dell'ecografia. Radiol Med 114:321-330

15. Samson F, Gorostiza I, González A, Landa M, Ruiz L, Grau M (2018) Prospective evaluation of clinical lung ultrasonography in the diagnosis of community-acquired pneumonia in a pediatric emergency department. Eur J Emerg Med 25(1):65-70. https ://doi.org/10.1097/MEJ.0000000000000418

16. Pereda MA, Chavez MA, Hooper-Miele CC, Gilman RH, Steinhoff MC, Ellington LE et al (2015) Lung ultrasound for the diagnosis of pneumonia in children: a meta-analysis. Pediatrics 135:714-722

17. Lichtenstein D, Mezière G, Seitz J (2009) The dynamic air bronchogram: a lung ultrasound sign of alveolar consolidation ruling out atelectasis. Chest 135:1421-1425

18. Wang G, Ji X, Xu Y, Xiang X (2016) Lung ultrasound: a promising tool to monitor ventilator-associated pneumonia in critically ill patients. Crit Care 20(1).

19. Reissig A, Copetti R, Mathis G, Mempel C, Schuler A, Zechner $P$ et al (2012) Lung ultrasound in the diagnosis and follow-up of community-acquired pneumonia: a prospective, multicenter, diagnostic accuracy study. Chest 142(4):965-972

20. Caiulo VA, Gargani L, Caiulo S et al (2013) Lung ultrasound characteristics of community-acquired pneumonia in hospitalized children. Pediatr Pulmonol 48(3):280-287. https://doi. org/10.1002/ppul.22585

21. Bouhemad B, Liu ZH, Arbelot C, Zhang M, Ferarri F, Le-Guen $\mathrm{M}$ et al (2010) Ultrasound assessment of antibiotic-induced pulmonary reaeration in ventilator-associated pneumonia. Crit Care Med 38(1):84-92

22. Musolino AM, Tomà $\mathrm{P}$, Supino $\mathrm{MC}$, Scialanga $\mathrm{B}$, Mesturino A, Scateni S, et al (2019) Lung ultrasound features of children with complicated and non complicated community acquired pneumonia: a prospective study. Pediatr Pulmonol ppul.24426.

23. Chiumello D, Mongodi S, Algieri I, Vergani GL, Orlando A, Via $\mathrm{G}$ et al (2018) Assessment of lung aeration and recruitment by CT scan and ultrasound in acute respiratory distress syndrome patients. Crit Care Med 46:1761-1768

24. Baldi G, Gargani L, Abramo A, D'Errico L, Caramella D, Picano E et al (2013) Lung water assessment by lung ultrasonography in intensive care: a pilot study. Intensive Care Med 39:74-84

25. Bouhemad B, Brisson H, Le-Guen M, Arbelot C, Lu Q, Rouby J-J (2011) Bedside ultrasound assessment of positive end-expiratory pressure-induced lung recruitment. Am J Respir Crit Care Med 183:341-347

26. Mongodi S, Pozzi M, Orlando A, Bouhemad B, Stella A, Tavazzi $\mathrm{G}$ et al (2018) Lung ultrasound for daily monitoring of ARDS patients on extracorporeal membrane oxygenation: preliminary experience. Intensive Care Med 44:123-124

27. Prat G, Guinard S, Bizien N, Nowak E, Tonnelier J-M, Alavi Z et al (2016) Can lung ultrasonography predict prone positioning 
response in acute respiratory distress syndrome patients? J Crit Care 32:36-41

28. Haddam M, Zieleskiewicz L, Perbet S, Baldovini A, Guervilly C, Arbelot C et al (2016) Lung ultrasonography for assessment of oxygenation response to prone position ventilation in ARDS. Intensive Care Med 42:1546-1556

29. Wang X-T, Ding X, Zhang H-M, Chen H, Su L-X, Liu D-W et al (2016) Lung ultrasound can be used to predict the potential of prone positioning and assess prognosis in patients with acute respiratory distress syndrome. Crit Care 20:385

30. Berlet T, Etter R, Fehr T, Berger D, Sendi P, Merz TM (2015) Sonographic patterns of lung consolidation in mechanically ventilated patients with and without ventilator-associated pneumonia: a prospective cohort study. J Crit Care 30:327-333

31. Claes A-S, Clapuyt P, Menten R, Michoux N, Dumitriu D (2017) Performance of chest ultrasound in pediatric pneumonia. Eur $\mathbf{J}$ Radiol 88:82-87

32. Gargani L, Volpicelli G (2014) How I do it: lung ultrasound. Cardiovasc Ultrasound 12:25

33. Narula J, Chandrashekhar Y, Braunwald E (2018) Time to add a fifth pillar to bedside physical examination: inspection, palpation, percussion, auscultation, and insonation. JAMA Cardiol $3: 346-350$

34. Soldati G, Smargiassi A, Mariani AA, Inchingolo R (2017). Novel aspects in diagnostic approach to respiratory patients: is it the time for a new semiotics? Multidiscip Respir Med. 12.

35. Soldati G, Demi M, Smargiassi A, Inchingolo R, Demi L (2019) The role of ultrasound lung artifacts in the diagnosis of respiratory diseases. Expert Rev Respir Med 13:163-172

36. Reissig A, Gramegna A, Aliberti S (2012) The role of lung ultrasound in the diagnosis and follow-up of community-acquired pneumonia. Eur J Intern Med 23:391-397

37. Mongodi S, Via G, Girard M, Rouquette I, Misset B, Braschi A et al (2016) Lung ultrasound for early diagnosis of ventilatorassociated pneumonia. Chest 149:969-980

38. Singh Y, Tissot C, Fraga MV et al (2020) International evidencebased guidelines on Point of Care Ultrasound (POCUS) for critically ill neonates and children issued by the POCUS Working Group of the European Society of Paediatric and Neonatal Intensive Care (ESPNIC). Crit Care 24(1):65. https://doi.org/10.1186/ s13054-020-2787-9

39. Volpicelli G, Elbarbary M, Blaivas M, et al (2012) International Liaison Committee on Lung Ultrasound for International Consensus Conference on Lung Ultrasound. International evidence-based recommendations for point-of-care lung ultrasound. Intensive Care Med. 38(4):577-591pmid:22392031.

40. Raimondi F, Migliaro F, Sodano A et al (2012) Can neonatal lung ultrasound monitor fluid clearance and predict the need of respiratory support? Crit Care 16(6):R220

41. Raimondi F, Migliaro F, Sodano A et al (2014) Use of neonatal chest ultrasound to predict noninvasive ventilation failure. Pediatrics 134(4):e1089-e1094

42. Brat R, Yousef N, Klifa R, Reynaud S, Shankar Aguilera S, De Luca D (2015) lung ultrasonography score to evaluate oxygenation and surfactant need in neonates treated with continuous positive airway pressure. JAMA Pediatr 169(8):e151797. https://doi. org/10.1001/jamapediatrics.2015.1797

43. Rodríguez-Fanjul J, Balcells C, Aldecoa-Bilbao V, Moreno J, Iriondo M (2016) Lung ultrasound as a predictor of mechanical ventilation in neonates older than 32 weeks. Neonatology 110(3):198-203. https://doi.org/10.1159/000445932

44. De Martino L, Yousef N, Ben-Ammar R, Raimondi F, ShankarAguilera S, De Luca D (2018) Lung ultrasound score predicts surfactant need in extremely preterm neonates. Pediatrics 142(3):e20180463. https://doi.org/10.1542/peds.2018-0463

Publisher's Note Springer Nature remains neutral with regard to jurisdictional claims in published maps and institutional affiliations. 